\title{
The use of external fixator for ankle and foot injuries management-a review on biomechanical perspective
}

\author{
Muhammad Hanif Ramlee ${ }^{1,2 *}$ and Azura Derus ${ }^{3}$ \\ ${ }^{1}$ Department of Electrical, Electronic and System Engineering, Faculty of Engineering and Built Environment, Universiti Kebangsaan Malaysia, 43600 UKM \\ Bangi, Selangor, Malaysia \\ ${ }^{2}$ Medical Devices and Technology Group, Faculty of Biosciences and Medical Engineering, Universiti Teknologi Malaysia, 81310 UTM Skudai, Johor, Malaysia \\ ${ }^{3}$ Department of Industrial Chemistry, Faculty of Industrial Sciences and Technology, Universiti Malaysia Pahang, Lebuhraya Tun Razak, 26300 Kuantan, Pahang, \\ Malaysia
}

\begin{abstract}
Current clinical services are very struggling to assist the most favourable treatment for ankle and foot injuries. Therefore, this inspired researchers and engineering to investigate and explore the important of biomechanical behaviour of an external fixator. However, the understanding on biomechanical of the external fixator is important point as it can contribute to the success of injuries treatment. This review article discusses an overview of the external fixator for ankle and foot injuries management. First and foremost, this paper addresses general features of the external fixator that includes configurations, materials used and overall construct stability. In addition, we also reviewed the use of external fixator in clinical applications. In conclusion, this report suggests some recommendation for future biomechanical studies in order to provide valuable information for researchers and medical experts.
\end{abstract}

\section{Introduction}

In clinical treatment, the main aims of ankle and foot injuries management are reconstruction and to accurate the anatomical conditions $[1,2]$. This includes minimally soft tissue invasive, early function and restoration, recreation of the joint surfaces and the most important is fast soft tissue healing [2-4]. To date, one of medical devices that normally used by surgeons is external fixator. In management of severe fractures among patients, the external fixator devices have contributed a significant role with extensive comminution or bone loss, limb lengthening, correction of osteotomies, ankle dislocation, nonunion treatment as well as correction of mal-alignment [5-13].

The use of external fixator for ankle and foot injuries is less invasive, can prevent complications and more favourable than internal fixator $[3,14]$. This is due to the fact that the internal fixation can cause excessive invasive, second surgery, plate infections and the system failed $[5,15,16]$. Moreover, the other advantages of using external fixator can decreases operative time as well as decreases the amount of soft tissue dissection $[5,14,17,18]$. To be noticed that the surgeon can avoid placement of the fixator in infected areas such as fractures [3]. The external fixator can provide neutralization and rigid stabilization which the advantages of adjustable amounts of distraction, compression, rotation and translation as necessary during the treatment $[1,2,19,20]$. In term of long term mobility of ankle joint, this ability is a significant advantage as compared than the internal fixator which the external fixation can provide the ability to bear weight without cast immobilization $[3,21]$. In addition, the management of severe injuries to the ankle and foot with external fixator is proven to be minimally invasive. This can further reducing devascularisation [22] and helps maintain alignment $[3,23,24]$ and maintain stability of the ankle joint [2,25-27].
For treating ankle and foot injuries, the understanding of the biomechanics of external fixator in one of key points to success. When doctors often use the correct fundamental of biomechanics, it can reduce some complications during the treatment $[1,28,29]$. To be noted, the maintenance of the external fixator alignment with early soft tissue coverage and allows early bone healing $[3,24]$. Furthermore, the external fixator can provide stability, simple and also allow soft tissue management in good access, however the fundamental of position and pin placement should be understood well $[2,25]$. This is due to the fact that pin site infection is normally reported by previous literature to occur with the use of external fixation (37\% of cases) [25,30,31]. Improper pins position on the bone can cause to infections or other complications. Nevertheless, the use of external fixator remain valuable for surgeons to manage ankle and foot injuries as the previous study by Nemec et al. [32] investigated 39 patient with war injuries of ankle and foot and found that the external fixator can prevent severe contractures as well as facilitated fracture healing. Although the external fixation may help maintain the position of the fracture and correct alignment of the ankle and foot, it should noticed that by understanding in biomechanics of external fixator can prevent worst scarring and subsequent contracture,

Correspondence to: Dr. Muhammad Hanif Ramlee, Department of Electrical, Electronic and System Engineering, Faculty of Engineering and Built Environment, Universiti Kebangsaan Malaysia, 43600 UKM Bangi, Selangor, Malaysia, Tel: +60126754717; E-mail: mhanif008@gmail.com

Key words: external fixator, stability, biomechanics, mechanical, finite element, configurations, complications

Received: August 12, 2016; Accepted: September 02, 2016; Published: September 05,2016 
In this review, we summarised the available data in previous published literature in terms of biomechanics of external fixator for ankle and foot injuries management. The aims of the review are as follows:

- To provide an overview of the external fixator used in treating ankle and foot injuries

- To identify the important of biomechanical strategy in terms of stability to prevent complications of external fixator.

- To supply recommendation for future research that is useful for providing addition information to surgeons relating the use of external fixator for treating ankle and foot injuries.

\section{Methods}

\section{Literature search strategy}

In this review, searches were conducted based on specific keywords and search engines, thus can optimize the time for reviewing period. Therefore, the following strategies were utilized in order to review current evidence from the literature:

Keywords used: the keywords included "external fixator" or "external fixation" and specific terms such as "stability", "biomechanics", "mechanical", "finite element", "configurations" and "complications".

Search engines: Web of Science, ScienceDirect, PubMed/Medline and Google Scholar

\section{Inclusion and exclusion criteria}

This review was conducted followed by some inclusion and exclusion criteria. For the inclusion, the previous literature and studies were included if they met the following criteria: (1) Articles published in English only; (2) The literature included the biomechanical aspects; (3) The studies' observation endpoint was the onset of the external fixator.

For the exclusion, these are based as follows: (1) The studies examined comparison between geography or country was not included; (2) The use of external fixator on animal experiments were exclude; (3) Duplicate publications.

\section{General features of the external fixator}

\section{Configurations}

The configurations of external fixator normally depend on the ankle injuries and surgeons' expertise. Basically, frame design or construct requires a combination of wires, pins, rods, clamps and rings to ultimately assemble a stable construct $[3,14,30]$. The various pins including transfixion wire, tapered cortical half-pin, trocar-tip tapered half-pin, self-drilling tapered, self-drilling cylindrical and cancellous tapered [14,33-36]. To be noticed, pin insertion technique is important to be chosen by surgeons as it can improve the initial pin torque resistance in order to minimize pin loosening [37]. Another part of external fixator is clamps which link a pin or wire to a rod or ring. Usually, a simple clamp connects one pin to a rod, whereas modular clamps may connect multiple pins to rod [38-40].

There were numerous external fixation in the market and used in clinical setting including uniplanar, multiplanar, articulated or hinged, hybrid and Ilizarov frame [4,41-49]. For the uniplanar external fixator, this only involves one or two rods that constructed with some number of clamps and pins. From previous published literature, the unilateral frame often used in treating subtalar dislocation and pilon fractures $[3,24]$. Unlike the unilateral, multiplanar is a combination of two or more planar used in the construct $[46,50,51]$. This configuration generally applied with two rods, two pins, a multiple pin clamp and several pinto-bar clamps [51,52]. In treating ankle problems, multiplanar external fixator normally applied pins through tibia, calcaneus and at the first metatarsal bone [51]. For articulated or hinged external fixator, this is a frame with rods that can allow movements through an articulated hinge [33]. The position of pin placement normally at the tibia and calcaneus, nevertheless, the application of the articulated external fixator to the ankle joint should be in appropriate angles to avoid complications of valgus deformity. Hybrid frame, on the other hand, is a combination of periarticular tensioned fine wire attached to a ring with traditional distal metaphysic or diaphysis half pins. In this configuration, a transfixion pin passing through the calcaneal that serve the distal link of the hybrid configuration. Something similar with Hybrid frame, Ilizarov frame also use rings and fine wire but there is no traditional pins or rods in the construct $[53,54]$. The Ilizarov external fixator is ideally consists of two-level fixation in each segment of the fracture bone and would be made up of four connected rings where each rings secured to the bone with tensioned wires. The ring construct consisted additional multiplanar stability which allows for a multitude of fixation options. From this construction, it has difficutly to assemble intraoperatively due to the fact that the limb must be properly positioned within the fixator while wires are driven, fixated and tensioned from different angles at the bone [55].

\section{Materials used}

External fixator that consists of pins, rods, rings and clamps has different materials used. Normally the external fixator has been composed of stainless steel, titanium alloy, aluminium alloy or carbon fiber $[14,56]$. From biomechanical point of view, different material properties affect the stability of the external fixator construct. This was shown by previous published literature by Kowalski, et al. [57] who found that carbon fiber rods were able to sustain higher loads without failing when compared to stainless steel tubes. The study indicated that carbon fiber rods demonstrated $15 \%$ stiffer that the stainless steel, therefore the construct were enough to sustain more loads. However, the use of titanium pins is proven to reduce stiffness, but using a construct made of titanium can significantly decrease the weight of the external fixator without decreasing its stiffness [19]. In addition, the use of carbon rods as a temporary triangular transfixation is very recommended by medical surgeons in order to enable preoperative computed tomography (CT) scan after soft tissue recovery, due to the fact that less image noise as compared with titanium alloy and stainless steel [58]. Nevertherless, future research on biomechanical evaluation of different materials of the external fixator should be conducted in order to provide addition information in terms of stability and load transmission.

\section{Overall construct stability}

Stability of external fixator is one of factors that contribute to final outcome in clinical treatment. To be noted, the use of stable external fixator is another successful of ankle injuries treatment where it can reduce many complications such as mal-union, non-union and infections [18]. In addition, previous studies showed the healing time is affected by the stiffness of external fixator where the longest healing time was found at the lowest fixation stability [20,59].

The methods to increase stiffness of the external fixator include using stiffer components, increasing the distance between pins within 
a bony fragment, increasing the pin diameter and pin number, pins should be spread, decreasing the distance of rod to bone, incorporating an additional rod, creating a bilateral system, decreasing the free bending length of the pins and aligning the plane of the pins with the major bending axis of the bone [19,20,29,60-62]. The stiffness of the external fixator in the axial and shear directions was found influenced by the stiffness of the pins, the fixator configuration and the connection clamps between them [63]. Increasing the number of pins can distributes the force and stress among the pins, therefore increases the stiffness of the overall frame. However, additional pins can increase the risk of damaging anatomic structure and provide more infection.

For hybrid and Ilizarov configuration, the bone-pin or bone-wire interface is important in attaining a stable frame for fracture fixation, stability and healing $[1,14]$. This is because of increased stiffness could be achieved by increasing wire or pin diameter, increasing the distances between the wires or pins, increasing the wire tension, positioning the proper wire-crossing angle $\left(90^{\circ}\right.$ is more stiff compared to $\left.45^{\circ}\right)$ and decreasing the bone to ring or bone to rod distance [64]. We believe that biomechanical analysis of different external fixator is necessary for surgeons and medical experts to choose the best construct in treating ankle and foot injuries thus can prevent complications in the future $[65,66]$.

It should be noticed that improper placement of the pins may interrupt muscles, tendons, and neurovascular structures $[2,20]$. The pin placement, configuration and material of the external fixator construct should be considered before any surgery can be conducted. This goal is to maintain and align hindfoot to leg relationship, and to properly fixed the ankle bone and stabilize the affected joints $[3,24]$. The faulty biomechanics that result have a significant role in osseous and ligamentous breakdown [5]. For the use of the hinged external fixator, it is important for surgeons and researchers to know that there is an optimal arrangement that will allow ankle motion while minimizing potentially disruptive forces at the calcaneal fracture interface. The study by Besch et al. [28] shows that optimal tibial screw placement for hinged external fixator was $70 \mathrm{~mm}$ proximal to the rotation axis of the upper ankle joint and optimal placement of screw was in the posterior surface of the calcaneus.

\section{Clinical applications and results}

In the ankle and foot injuries management, the external fixation can be used for a wide range of clinical applications such as to treat fractures, deformities and dislocations pathological problem $[3,7,24,53]$. However, some ankle fractures treatment involves initial closed reduction and stabilization of the injury by external fixation followed by delayed internal fixation $[67,68]$. The use of external fixation is favourable compared with internal fixation as it can allow for rigid fixation and maintenance of reduction in unstable injuries. In the treatment of intra-articular calcaneus fractures Besch, et al. [15] uses hinged external fixator to treat two hundred-fourteen patients between 1993 and 1998. The results from their study suggested that the correct treatment of this pathology problem is using a hinged external fixator. For the seriously injury such as talar fracture, Ilizarov external fixator is recommended to manage the treatment [47]. Singh et al. [47] use Ilizarov frame to reduce talar fracture where two rings were applied to the lower leg and a foot plate was applied with wires were appropriated tensioned. The result showed that the patient was normal and his ankle healed in good alignment and anatomical position with good range of motion, without pain and with normal ambulation. The use of external fixator is also applicable for avascular necrosis in the talus management after the talar fracture. Janis et al. [49] use Orthofix external fixator in order to treat avascular necrosis of the talus and the results were good in maintaining the alignment of the ankle joint.

The challenge in clinical treatment for deformities problem also can be solved by using external fixator construct. Nishimura et al. [42] attempted to treat the Hallux valgus deformity with an Ilizarov external fixator for 10 patients in 20 feet. The basal metatarsal osteotomy is fixed by two Kirscher wires $1.8 \mathrm{~mm}$ in diameter followed by Illizarov consists of olive wires $1.5 \mathrm{~mm}$ in diameter, six wire-fixing bolts and weighs no more than about $200 \mathrm{~g}$. All patients were able to walk without crutches within 1 week of operation and only three feet was observed in complications. Takata et al. [43] treated foot deformity with hexapod external fixator, Ortho-SUV frame (OSF) for 9 patients. The construct were removed with an average of 152 (range 22 to 286) days after the surgical procedure. The results found that all deformities problem were corrected and there were no pin-tract infection. However, disadvantages of hexapod fixator included their bulkiness and hemilaterally assembled construct could result in a slight bending of the frame. Nevertheless, the use of hexapod is favourable as it can make a correction of multiplanar deformities simultaneously but in Ilizarov remain difficult. Alkhooly et al. [4] made own external fixator to treat clubfoot deformity for 32 feet from Aug 1992 to Feb 2001 and the overall treatment time ranged from 10 to 12 weeks [4]. They found that twenty-three feet had excellent (71.9\%), eight feet had good results (25\%) with mild residual adduction because the side bar of the fixator was not fixed in the correct position early and one foot with a poor result (3.1\%). Furthermore, the author claims that the problem is solved in advantages of permitting dressing of the wounds (good skin coverage and wound healing), maintenance of the correction, and observation of the circulation and prevention of neurovascular complications by gradual correction when needed.

\section{Directions for future research}

Despite the previous published literature provide valuable information on the use of external fixator, however, extensive future research work is still needed. This can provide prescriptive advice peculiarly for specific problems (i.e. subtalar dislocation and pilon fractures) for better understanding. Based on author's knowledge and expertise, the following suggestions can be considered in advancing new research for the future:

A biomechanical study can be conducted by using finite element model in order to determine stress, forces, deformation on the ankle joints (Figure 1) [69]. These can predict the magnitude values inside the human body which is very difficult when conducting experimental using cadaveric specimen. For example, previous finite element analysis has been done in investigating the biomechanical features for

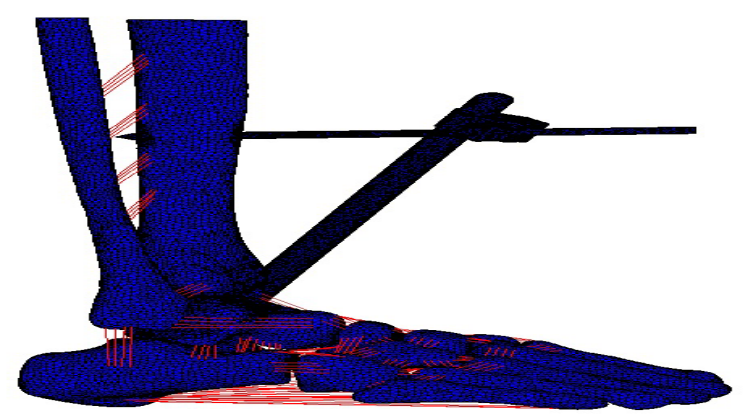

Figure 1. Ankle and foot finite element model fixated with unilateral external fixator. 
treating subtalar dislocation and pilon fractures $[66,70]$. To be noted, the use of finite element analysis can provide engineering information in designing new implant or medical devices. Furthermore, finite element results of stress on bone (which is difficult to conduct using experiment) can provide an overview and understanding to prevent complications in treating ankle and foot injuries. To date, there is very little data available in the literature regarding the finite element results that can support the choices of external fixator for specific pathological problems. Therefore, we believe that finite element method is very useful to predict the outcome of external fixator used in terms of biomechanical aspect.

Undoubtedly, it is very difficult to secure cadaveric specimen for conducting biomechanical experiment to investigate the use of external fixator. To be noticed that in securing cadaveric require special medical ethics, storage, preparation and expertise to handle the specimen. Therefore, instead of using cadaveric, the experiment can be conducted by using polyurethane physical model as shown in Figure 2. As shown from previous literature, the use of polyurethane model is acceptable and more convenient compared with cadaveric specimen [28,71].

\section{Limitation of this review}

We have attempted to highlight the biomechanical features in the use of external fixator for the ankle and foot injuries management. We believe that this review provide a concise literature that aimed to better understanding the biomechanical aspect. Nevertheless, there are some limitations that need to be considered in this review. First and foremost, this review only include general features of external fixator especially for ankle and foot treatment in terms of configuration, materials used and stability of the construct. Secondly is the use of external fixator in clinical practices. Topics related to the external fixator outside of those described earlier were not discussed in this review. However, we believe that this review can assist future research to be conducted for better understanding on the external fixator used.

\section{Conclusion}

The choice of which external fixator to be used in treating ankle and foot injuries normally is depend on the clinical situation and medical experts. The treatment must best undertake at a tertiary care facility, especially before the surgery can be conducted. The understanding of the biomechanical behaviour of the external fixator during treatment is necessary to prevent complications. Future biomechanical study for an ankle external fixator should be investigated to provide addition

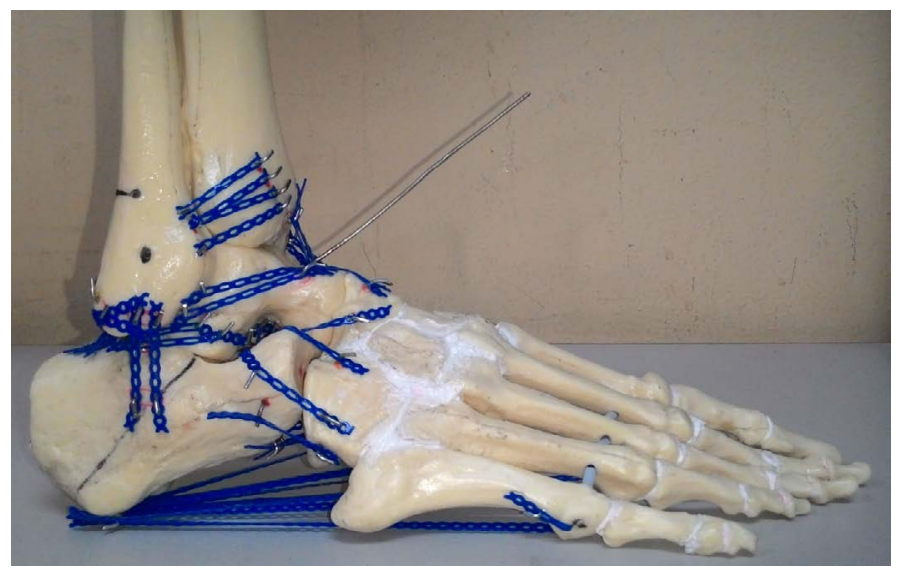

Figure 2. Polyurethane model of ankle and foot. information and understanding as well as can support the choices of the fixator construct.

\section{Acknowledgement}

The work has been carried out with the support of research funding from Centre for Research and Innovation Management (CRIM), Universiti Kebangsaan Malaysia and University Grant, Universiti Kebangsaan Malaysia

\section{Conflicts of interest}

There are no conflicts of interest.

\section{References}

1. Atesalp AS (2001) Reconstruction with circular external fixator in massive calcaneal destructions due to land mine injury. Foot and Ankle Surgery 7: 23-29.

2. Seibert FJ (2003) External fixation in trauma of the foot and ankle. Clinical Podiatric Medicine and Surgery 20: 159-180.

3. Ansah M, Sella EJ (2000) Treatment of complete open medial subtalar dislocation with an external fixator. Foot and Ankle Surgery 6: 179-184.

4. Alkhooly AZAA (2003) Eight year's experience with soft tissue release and Alkhooly external fixator in the treatment of resistant clubfoot. Fuss and Sprunggelenk 1: 199-207.

5. Sayner LR, Rosenblum BI (2005) External fixation for Charcot foot reconstruction. Curr Surg 62: 618-623. [Crossref]

6. Erdogan B, Gorgu M, Girgin O (1996) Application of external fixators in major foo contractures. J Foot Ankle Surg 35: 218-221. [Crossref]

7. El-Alfy B (2010) Arthrodesis of the ankle joint by Ilizarov external fixator in patients with infection or poor bone stock. Foot Ankle Surg 16: 96-100. [Crossref]

8. Paley D, Lamm BM (2004) Correction of the cavus foot using external fixation. Foo Ankle Clin 9: 611-624. [Crossref]

9. Ferreira RC, Costo MT, Frizzo GG, da Fonseca Filho FF (2006) Correction of neglected clubfoot using the Ilizarov external fixator. Foot Ankle Int 27: 266-273. [Crossref]

10. Cooper PS (2002) Application of external fixators for management of Charcot deformities of the foot and ankle. Foot Ankle Clin 7: 207-254. [Crossref]

11. Schiedel F, Vogt B, Wacker S, Pöpping J, Bosch K, et al. (2012) Walking ability of children with a hexapod external ring fixator (TSF®) and foot plate mounting at the lower leg. Gait Posture 36: 500-505. [Crossref]

12. Paley D (1990) Problems, obstacles, and complications of limb lengthening by the Ilizarov technique. Clin Orthop Relat Res: 81-104. [Crossref]

13. Hiraizumi Y, Hara T, Takahashi M, Mayehiyo S (1992) Open total dislocation of the talus with extrusion (missing talus): report of two cases. Foot Ankle 13: 473-477. [Crossref]

14. Moss DP, Tejwani NC (2007) Biomechanics of External Fixation. A review of the literature. Bulletin of the NYU Hospital for Joint Diseases 65: 297-299.

15. Besch L, Waldschmidt JS, Daniels-Wredenhagen M, Varoga D, Mueller M, et al (2010) The treatment of intra-articular calcaneus fractures with severe soft tissue damage with a hinged external fixator or internal stabilization: long-term results. J Foot Ankle Surg 49: 8-15. [Crossref]

16. Ilizarov G (1954) New principles of osteosynthesis by means of crossing pins and rings. Russin Internal Publication Book.

17. Sirkin M, Sanders R, DiPasquale T, Herscovici D (2004) A staged protocol for sof tissue management in the treatment of complex pilon fractures. J Orthop Trauma 18: S32-38. [Crossref]

18. Talarico LM, Vito GR, Zyryanov SY (2004) Management of displaced intraarticular calcaneal fractures by using external ring fixation, minimally invasive open reduction, and early weightbearing. Journal of Foot and Ankle Surgery 43: 43-50.

19. Briggs BT, Chao EY (1982) The mechanical performance of the standard HoffmannVidal external fixation apparatus. The Journal of Bone and Joint Surgery. American volume 64: 566-573.

20. Wehner $T$ (2010) Influence of the fixation stability on the healing time- A numerical study of a patient-specific fracture healing process. Clinical Biomechanics 25: 606-612. 
21. El Ghawabi MH (1978) Centripetal compression triple arthrodesis. Acta Orthop Scand 49: 306-309. [Crossref]

22. Myerson MS, McGarvey WC, Henderson MR, Hakim J (1994) Morbidity after crush injuries to the foot. J Orthop Trauma 8: 343-349. [Crossref]

23. Pinney SJ, Sangeorzan BJ (2001) Fractures of the tarsal bones. Orthop Clin North Am 32: 21-33. [Crossref]

24. Cheema GS (2011) The results of two-staged operative management of pilon fracturesa review of 25 cases. Journal of Orthopaedic and Trauma 2: 104-108.

25. Kenzora JE, Edwards CC, Browner BD, Gamble JG, DeSilva JB (1981) Acute management of major trauma involving the foot and ankle with Hoffmann external fixation. Foot Ankle 1: 348-361. [Crossref]

26. Beals TC (2001) Applications of ring fixators in complex foot and ankle trauma. Orthop Clin North Am 32: 205-214. [Crossref]

27. Yufit P, Seligson D (2010) Malleolar ankle fractures. A guide to evaluation and treatment. Orthopaedics and Trauma 24: 286-297.

28. Besch L (2008) A biomechanical evaluation to optimize the configuration of a hinged external fixator for the primary treatment of severely displaced intraarticular calcaneus fractures with soft tissue damage. The Journal of Foot and Ankle Surgery, 47: 26-33.

29. Behrens F, Johnson WD, Koch TW, Kovacevic N (1983) Bending stiffness of unilateral and bilateral fixator frames. Clin Orthop Relat Res: 103-110. [Crossref]

30. Hedin H, Hjorth K, Rehnberg L, Larsson S (2003) External fixation of displaced femoral shaft fractures in children: a consecutive study of 98 fractures. $J$ Orthop Trauma 17: 250-256. [Crossref]

31. Alonge TO, Ogunlade SO, Salawu SA, Adebisi AT (2003) Management of open tibia fracture--Anderson and Hutchins technique re-visited. Afr J Med Med Sci 32: 131-134. [Crossref]

32. Nemec B, Santic V, Matovinovic D, Gulan G (2000) War wounds to the foot. Mil Med 165: 18-20. [Crossref]

33. Bastini GD, Apley AG, Goldberg A (2000) Orthofix external fixator system in the foot and ankle. New York: Springer Verlag.

34. Chao EY, Aro HT, Lewallen DG, Kelly PJ (1989) The effect of rigidity on fracture healing in external fixation. Clin Orthop Relat Res: 24-35. [Crossref]

35. Drijber FL, Finlay JB (1992) Hoffmann half-frame external fixation rigidity and its relationship to universal joint slippage. Annals of Biomedical Engineering 20: 533-545.

36. Treadwell JR (2004) Triple arthrodesis with an external rail fixator: a review of 8 cases. J Foot Ankle Surg 43: 400-406. [Crossref]

37. Pettine KA, Chao EY, Kelly PJ (1993) Analysis of the external fixator pin-bone interface. Clin Orthop Relat Res: 18-27. [Crossref]

38. Chandran P, Puttaswamaiah R, Dhillon MS, Gill SS (2006) Management of complex open fracture injuries of the midfoot with external fixation. J Foot Ankle Surg 45: 308315. [Crossref]

39. Simon SR, Tejwani SG, Wilson DL, Santner TJ, Denniston NL (2000) Arthrodesis as an early alternative to nonoperative management of charcot arthropathy of the diabetic foot. J Bone Joint Surg Am 82-82A: 939-50. [Crossref]

40. Zgonis T (2006) Surgical management of the unstable diabetic Charcot deformity using the Taylor spatial frame. Operative Techniques in Orthopaedics 16: 10-17.

41. Wade R, Roberts S, Richardson J (1999) Simple techniques to prevent ankle equinus with external fixators. Physiotherapy 85: 248-250.

42. Nishimura N, Yamano Y (1997) Hallux valgus operation using Ilizarov external fixator. Foot and Ankle Surgery 3: 183-188.

43. Takata M, Vilensky VA, Tsuchiya H, Solomin LN (2013) Foot deformity correction with hexapod external fixator, the Ortho-SUV Frameâc. J Foot Ankle Surg 52: $324-$ 330. [Crossref]

44. Mayer G, Seidlein H, Hunfeld T (1996) Clubfoot correction by external ring fixator. Foot and Ankle Surgery 2: 223-227.

45. Fragomen AT (2008) A biomechanical comparison of micromotion after ankle fusion using 2 fixation techniques: Intramedullary arthrodesis nail of Ilizarov external fixator. Foot and Ankle International 29: 334-341.

46. Mendicino RW, Kim C, Kabazie AJ, Catanzariti AR (2008) Correction of severe foot and ankle contracture due to CRPS using external fixation and pain management: report of a pediatric case. J Foot Ankle Surg 47: 434-440. [Crossref]
47. Singh S (2010) Talar neck fracture reduced and stabilized with an Ilizarov external fixator: A case report with three year follow up. The Foot and Ankle Online Journal 3: $1-10$.

48. DeVries JG, Berlet GC, Hyer CF (2012) A retrospective comparative analysis of Charcot ankle stabilization using an intramedullary rod with or without application of circular external fixator utilization of the Retrograde Arthrodesis Intramedullary Nail database. J Foot Ankle Surg 51: 420-425. [Crossref]

49. Janis L, Krawetz L, Wagner S (1996) Ankle and subtalar fusion utilizing a tricortical bone graft, bone stimulator, and external fixator after avascular necrosis of the talus. $J$ Foot Ankle Surg 35: 120-126. [Crossref]

50. Mendicino RW, Murphy LJ, Maskill MP, Catanzariti AR, Penny H (2008) Application of a constrained external fixator frame for treatment of a fixed equinus contracture. $J$ Foot Ankle Surg 47: 468-475. [Crossref]

51. Mitkovic MB, Bumbasirevic MZ, Lesic A, Golubovic Z (2002) Dynamic external fixation of comminuted intra-articular fractures of the distal tibia (type $\mathrm{C}$ pilon fractures). Acta Orthop Belg 68: 508-514. [Crossref]

52. Schoenhaus HD, Lam S, Treaster A, Troiano M (2009) Use of a small bilateral external fixator for ankle fusion. J Foot Ankle Surg 48: 89-92. [Crossref]

53. Khanfour AA (2013) Versatility of Ilizarov technique in difficult cases of ankle arthrodesis and review of literature. Foot Ankle Surg 19: 42-47. [Crossref]

54. Gessmann J, Jettkant B, Schildhauer TA, Seybold D (2011) Mechanical stress on tensioned wires at direct and indirect loading: a biomechanical study on the Ilizarov external fixator. Injury 42: 1107-1111. [Crossref]

55. Hutchinson B, McCann K, Kirienko A (2010) The kickstand technique for circular external fixator assembly. J Foot Ankle Surg 49: 504-505. [Crossref]

56. Giotakis N, Narayan B (2007) Stability with unilateral external fixation in the tibia Strategies Trauma Limb Reconstr 2: 13-20. [Crossref]

57. Kowalski M (1996) Comparative biomechanical evaluation of different external fixation sidebars: stainless-steel tubes versus carbon fiber rods. Journal of Othopaedics and Trauma 10: 470-475

58. Zwipp H (1993) Osteosynthesis of displaced intraarticular fractures of the calcaneus Results in 123 cases. Clinical Orthopaedics and Related Research 290: 76-86.

59. Wehner T, Claes L, Niemeyer F, Nolte D, Simon U (2010) Influence of the fixation stability on the healing time-a numerical study of a patient-specific fracture healing process. Clin Biomech (Bristol, Avon) 25: 606-612. [Crossref]

60. Huiskes R, Chao EY (1986) Guidelines for external fixation frame rigidity and stresses. J Orthop Res 4: 68-75. [Crossref]

61. Naqui SZ, Thiryayi W, Foster A, Tselentakis G, Evans M, et al. (2008) Correction of simple and complex pediatric deformities using the Taylor-Spatial Frame. $J$ Pediatr Orthop 28: 640-647. [Crossref]

62. Rozbruch R (2010) Does the Taylor Spatial Frame accurately correct tibial deformities. Clinical Orthopaedics and Related Research 468: 1352-1361.

63. Schmickal T, Hoentzsch D, Wentzensen A (2008) Cadaver specimens investigation of three articulated external fixator types for the human ankle joint. An experimental study from the external fixation working group from German chapter of the $A O / A S I F$. INJURY 39: 485-490.

64. Podolsky A, Chao EYS (1993) Mechanical performance of Ilizarov circular external fixators in comparison with other external fixators. Clinical Orthopaedics and Related Research 29: 61-70.

65. Ramlee MH (2014) Finite element analysis of three commonly used external fixation devices for treating Type III pilon fractures. Medical Engineering and Physics 36: $1322-1330$

66. Ramlee MH (2014) Biomechanical evaluation of two commonly used external fixators in the treatment of open subtalar dislocation- A finite element analysis. Medical Engineering and Physics 36: 1358-1366.

67. Babis GC, Kontovazenitis P, Evangelopoulos DS, Tsailas P, Nikolopoulos K, et al (2010) Distal tibial fractures treated with hybrid external fixation. Injury 41: 253-258. [Crossref]

68. Mauffrey C, Vasario G, Battiston B, Lewis C, Beazley J, et al. (2011) Tibial pilon fractures: a review of incidence, diagnosis, treatment, and complications. Acta Orthop Belg 77: 432-440. [Crossref]

69. Ramlee MH, Abdul Kadir MR, Harun H (2014) Three-dimensional modeling and analysis of a human ankle joint. IEEE: 74-78. 
Ramlee MH (2016) The use of external fixator for ankle and foot injuries management-a review on biomechanical perspective

70. Ramlee MH, Abdul Kadir, Harun H (2014) Three-dimensional modelling and finite element analysis of an ankle external fixator. Advanced Materials Research 845: 183-188.
71. Clifford C, Berg S, McCann K, Hutchinson B (2015) A biomechanical comparison of internal fixation techniques for ankle arthrodesis. J Foot Ankle Surg 54: 188-191. [Crossref]

Copyright: (C2016 Ramlee MH. This is an open-access article distributed under the terms of the Creative Commons Attribution License, which permits unrestricted use, distribution, and reproduction in any medium, provided the original author and source are credited. 